Journal of Engineering and Applied Sciences 14 (Special Issue 3): 6122-6126, 2019

ISSN: 1816-949X

(C) Medwell Journals, 2019

\title{
Virtual Screening of Selected Sea Cucumber Compounds as Inhibitor Human Kinesin-8
}

\author{
Broto Santoso \\ Faculty of Pharmacy, Universitas Muhammadiyah Surakarta, Jl. Ahmad Yani Tromol Pos I, \\ 57102 Sukoharjo, Indonesia
}

\begin{abstract}
Indonesian coastal areas have $20 \%$ of sea cucumber species from a total of 1716 species in the world. Several chemical compounds in it have been tested as antitumor. One of them, stichoposide, induce apoptosis in leukemia and colon cancer cells. There are 45 selected chemical compounds in this organism that have a molecular weight range similar to natural compounds that have been proven to be antimitotic such as vinca and taxol. In silico method has been widely used for initial screening of compound activity. This study aimed to screen in silico active inhibitors against kinesin- 8 antimitotic protein by utilizing binding site pocket of taxol. The selected compounds and proteins were downloaded from the TCMSP and RCSB database, respectively. The test compounds that in the image format were converted into files that is ready to be used for screening. The software used were OSRA, MarvinSketch and Open Babel. Native ligands and proteins were prepared using chimera. Molecular docking was performed using DOCK6. The center of computational mass was obtained automatically through DOCK6 and the volume of the grid-box is made in 6 series including the value that is automatically gained. The selected volume variations have been carried out based on the results of the method validation using native ligand from protein. There are 3 and 5 volume variations for rigid and flexible ligands, respectively, based on the RMSD value of 5ogc's target that were used. The RMSD value shows that the molecular conformation closeness can be acquired well for the target protein $5 \mathrm{ogc}$ in flexible search and has met the criteria of the RMSD value less than the maximum limit. Almost all tested compounds show their inability to do in silico bonds with target proteins, except for HPG-7 and CEG-3 compounds. Both have the best docking score for $87 \%$ of the total variation(HPG-7) and $100 \%$ of the total variation(CEG-3) in the flexible search method. They have greater binding affinity than the taxol docking score. In other side, stichoposide $(-56.18-(-50.42) \mathrm{kcal} / \mathrm{mol})$ do not provide better results in ligand-protein interactions than taxol (-72.05-(-64.61) $\mathrm{kcal} / \mathrm{mol})$ as antimitotic.
\end{abstract}

$\underline{\text { Key words: Docking, sea cucumber, antimitotic, DOCK6, anticancer, chimera }}$

\section{INTRODUCTION}

Sea cucumber is abundant in Indonesia, especially in coastal area. Teripang is a term for traded sea cucumber. Indonesia has 350 species of sea cucumber that are reported and recorded well (Pangestuti and Arifin, 2018; Setyastuti and Purwati, 2015). In the world, in 2011 there were 1200 species of sea cucumber and 66 of them were eripang which were included in the world trade list (Purcell et al., 2013). This year's report stated that the number of sea cucumber has reached 1716 species in the world (Pangestuti and Arifin, 2018). Teripang, in the world, there are 1400 species and Indonesia has 54 species or around $82 \%$ of the species that become world trade commodities and there are only 33 species that their names have been validated. Indonesian teripang was growth and distributed in most of the coastal of the islands of Eastern Indonesia such as Lombok, East
Kalimantan, Sulawesi, Maluku, Papua, Nusa Tenggara Timur (NTT) and Nusa Tenggara Barat (NTB). Abdullah Rasyid tells that Indonesia has $20 \%$ of teripang species from 1250 species in the world. Teripang contains omega 3 , glucosamine, chondroitin and mucopolysaccharides which are useful for brain development, joint pain and help in the formation of cartilage.

Teripang has been widely studied as a source of medicinal compounds. Some biological activities have been found such as antioxidants, antiinflammatory, antitumor, antiproliferative, anticoagulant and antiviral. Extract of teripang showed inhibitory activity against several cancer cells including human cervical cancer (HeLa) and human breast cancer (MCF-7). Some compounds which are triterpene glycosides, namely leucospilota side A, leucospilota side $\mathrm{B}$, leucospilota side $\mathrm{C}$, echinoside $\mathrm{B}$, holothurin $\mathrm{A}$, holothurin $\mathrm{B}$, holothurin $\mathrm{B} 2$ gave a deadly effect to cancer cells like human lung 
carcinomana (A549) and skin melanoma (B16F10). Stichoposide A and B was reported to inhibit cancer cell growth Hepatoma (Hep-G2), epidermoid (KB), prostate (LNCaP), MCF-7 and SK-Mel2 (Cuong et al., 2017). Stichoposide $\mathrm{C}$ and $\mathrm{D}$ show anticancer activity against Leukemia cells (HL-60) and murine Colorectal Tumor cells (CT-26) (Park et al., 2012; Yun et al., 2012).

By molecular weight filtering, there are 45 compounds that have been chosen from sea cucumber database of Traditional Chinese Medicine System Pharmacology (TCMSP) based on molecular weight of taxol. This natural product, similar action with vinca has been proven as antimitotic until now. Molecular weight is one of descriptor can be used as initial molecular screening in silico approach. Previous studies have shown that with the help of this technique, there is a positive correlation between the results of reverse docking and the antidiabetic assay of zerumbon Santoso et al. and Sakika et al. and many more publications state that in silico methods can reveal potential activities of target compounds. There are not many target proteins of anticancer with taxol as a ligand that can be found in a Protein Data Bank (PDB) as managed by Research Collaboratory for Structural Bioinformatics (RCSB). One of them that can be used as target is kinesin- 8 protein. This study aimed to screen in silico active inhibitors against kinesin- 8 antimitotic protein by utilizing binding site pocket of taxol.

\section{MATERIALS AND METHODS}

This research was done in several stages. There are preparation of test compounds and target proteins, chimera application to the target proteins, molecular docking of ligands against protein, visualization and data analysis of screening results. The following description are details of each step.

Collecting test compounds and target protein: For sea cucumber, there are 586 compounds that were successfully collected inTCMSP database (Table 1). Molecular weight of taxol is $853.9 \mathrm{~g} / \mathrm{mole}$. Its value was used as a reference to determine the chosen compounds for molecular docking. The selected of 45 compounds which have molecular weight between 750-1000 g/mole and three proteins (5oam, $50 \mathrm{ocu}$ and $5 \mathrm{ogc}$ ) were downloaded from the TCMSP and RCSB database, respectively. Unfortunately, all test compounds are in the image format. First, they were converted into files that is ready to be used for screening using Optical Structure Recognition (OSRA) online version. Marvin Sketch was used to convert these results to three-dimensional molecular form. Last step in preparation of test compound was combining all molecules into one file by merging them using Open Babel. The final file consists of 45 molecules with mol 2 type extension which is required by molecular docking applications. Target protein and its native were treated further to get the files needed by DOCK6. These tasks were completed by chimera.

Protein preparation: Taxol as native ligands was separated from its protein thenadded hydrogen atom, adjusted to appropriate charge and saved as mol2 type extensionusing chimera applications. Each target proteins were done the same thing with native using DockPrep feature in chimera. There are two type files were generated from this process, mol2 and pdb which no hydrogen atom in the final molecule. Their molecular surface was produced and saved as dms type file. In this step, incomplete side chain's protein was corrected by online Dunbrack library.

Molecular docking: Molecular docking was performed using the center of computational mass was obtained automatically through DOCK6. The grid-box volumeswere made in 6 series (Table 2) including the value that was automatically gained by software it selves. The selected volume variations have been carried out based on the results of the method validation using native ligand of protein.

Table 1: Groups of molecular weight of compounds contained in sea cucumber

\begin{tabular}{lcl}
\hline Molecular weight $(\mathrm{g} /$ mole) & Amounts & Data range $(\mathrm{g} / \mathrm{mole})$ \\
\hline$<500$ & 62 & $304.5-498.70$ \\
$500-750$ & 180 & $500.8-699.00$ \\
$750-1000$ & 45 & $751.1-985.20$ \\
$\geq 1000$ & 299 & $1021.5-1913.8$ \\
\hline
\end{tabular}

Table 2: Dimension size $(\AA)$ of grid-box volume of target protein

\begin{tabular}{|c|c|c|c|c|c|c|c|c|}
\hline \multicolumn{3}{|c|}{ 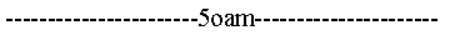 } & \multicolumn{3}{|c|}{ 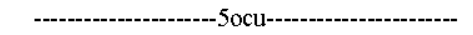 } & \multicolumn{3}{|c|}{ - } \\
\hline$\underline{x}$ & $\mathrm{y}$ & $\mathrm{z}$ & $\mathrm{x}$ & $\mathrm{y}$ & $\mathrm{z}$ & $\mathrm{x}$ & $\mathrm{y}$ & $\mathrm{z}$ \\
\hline 31.455 & 38.034 & 35.897 & 30.392 & 37.984 & 35.15 & 33.428 & 41.043 & 35.371 \\
\hline 28.955 & 35.534 & 33.397 & 27.892 & 35.484 & 32.65 & 30.928 & 38.543 & 32.871 \\
\hline 26.455 & 33.034 & 30.897 & 25.392 & 32.984 & 30.15 & 28.428 & 36.043 & 30.371 \\
\hline 23.955 & 30.534 & 28.397 & 22.892 & 30.384 & 27.65 & 25.928 & 33.543 & 27.871 \\
\hline 21.455 & 28.034 & 25.897 & 20.392 & 27.884 & 25.15 & 23.428 & 31.043 & 25.371 \\
\hline$\underline{18.955}$ & 25.534 & 23.397 & 17.892 & 25.384 & 22.65 & 20.928 & 28.543 & 22.871 \\
\hline
\end{tabular}


Validation of docked position of native was determine by its RMSD value. Based on the RMSD value of 5 ogc's target, there were 3 (series 1-3) and 5 (series 1-5) variations of volume used for rigid and flexible ligands, respectively. Two other proteins did not comply the maximum limit value.

\section{RESULTS AND DISCUSSION}

A good system of molecular docking must be able to imitate the conformation of native ligand on its protein.
Previous unpublished research showed that DOCK6 has tolerable limits for RMSD values $<5$ in order to declare docked ligand to have a position similar to the native ligand. Validation the system is important to be done to make the docking result closer to the its actual value. It can increase certainty of a predictive approach. Protein 5oam for rigid and flexible mode.

Validation of docking system: Figure 1 and 2a present result of molecular docking system that must be avoided. They have RMSD value higher than five, dominantly. In

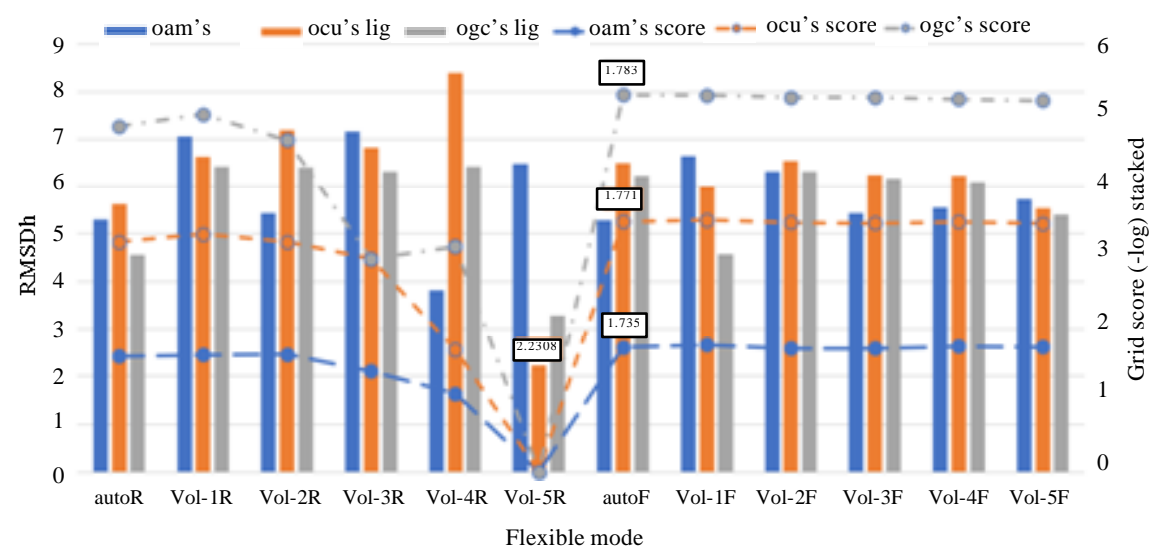

Fig. 1: RMSDh value versus grid score of native ligand on protein 5oam for rigid and flexible mode
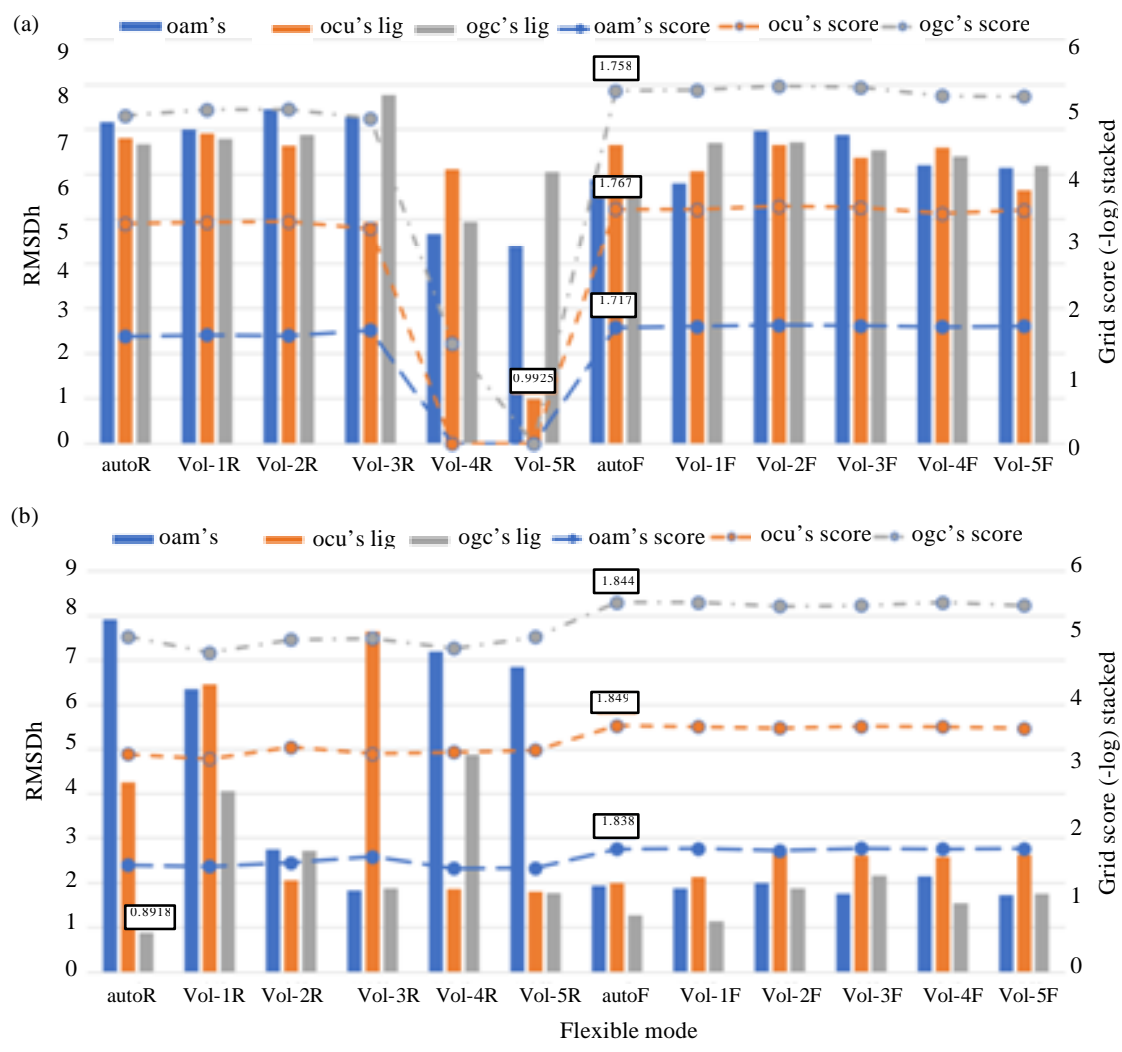

Fig. 2: RMSDh value and grid score of native ligand on protein: a) 5 ocu for rigid and b) 5 ogc for flexible mode 
contrast, Fig. $2 \mathrm{~b}$ shows their RMSD value reach $83 \%$ have met the requirement. Protein $5 \mathrm{ogc}$ is recommended to use for next molecular docking. All figures illustrate that rigid ligand technique gave a fluctuate grid score than the flexible one.

The highest grid score of native was shown by protein of $5 \mathrm{ogc}$ with flexible mode. Other proteins display $<5$ ogc's grid score but both of them exhibit the same results. These validation data confirm that protein of 5 oge must be used and chosen for screening of ligand activity of human kinesin-8.

Molecular docking results: Figure 3 a reveals that there are few compounds which have grid score better than native ligand for protein $5 \mathrm{oam}$ and $5 \mathrm{ocu}$. In opposite, test ligands have high percentage of grid score that surpass value of their native ligand. Anomaly results were found on protein 5 oge and best two for test ligands with flexible mode is shown in Table 3.

Almost all tested compounds show their inability to do in silico bonds with target proteins, except for HPG-7 and CEG-3 compounds as shown in Fig 3b. Both have the best docking score for $87 \%$ of the total variation (HPG-7) and $100 \%$ of the total variation (CEG-3) in the flexible search method. They have greater binding affinity than the taxol docking score. In other side, stichoposide $(-56.18-(-50.42) \mathrm{kcal} / \mathrm{mol})$ do not provide better results in ligand-protein interactions than taxol $(-72.05-(-64.61) \mathrm{kcal} / \mathrm{mol})$ as antimitotic.

(a)

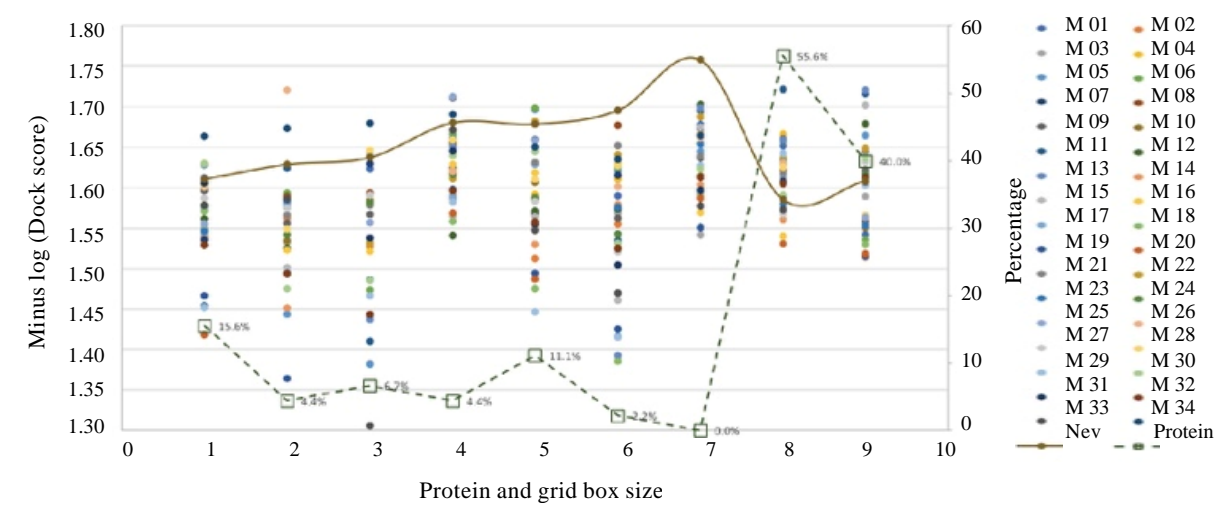

oam's type 0 (1), 1 (2), 2 (3); ocu's type 0 (4), 1 (5), 2 (6); cgc's type 0 (7), 1 (8), 2 (9)

(b)

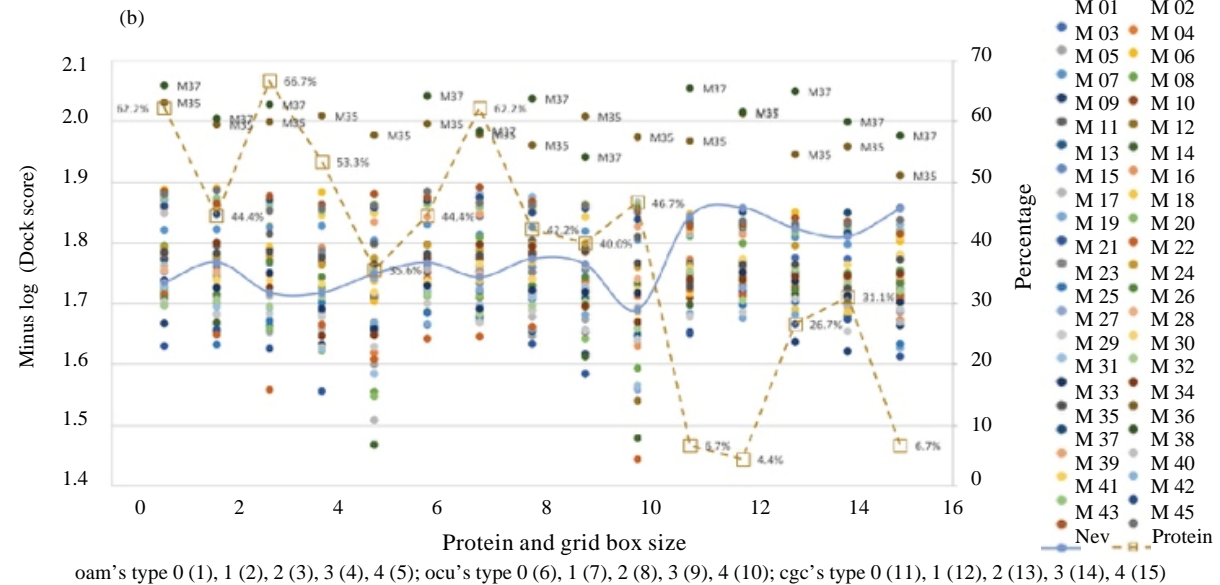

Fig. 3: Grid score of test ligands versus grid-box size for: a) Rigid dock result verses gridbox size of ducking and b) Flexible mode result verses gridbox size of ducking

Table 3: The grid score ( $\mathrm{kcal} / \mathrm{mole})$ of best of two test ligands against target protein with flexible mode of docking

\begin{tabular}{|c|c|c|c|c|c|c|c|c|c|c|c|c|c|c|c|}
\hline \multirow[b]{2}{*}{ Mol. } & \multicolumn{5}{|c|}{ 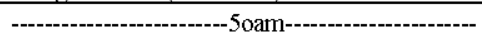 } & \multicolumn{5}{|c|}{ 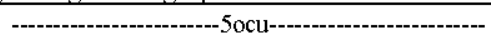 } & \multicolumn{5}{|c|}{ 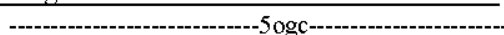 } \\
\hline & $\mathrm{S}-1$ & $\mathrm{~S}-2$ & $\mathrm{~S}-3$ & S-4 & S-5 & $\mathrm{S}-1$ & $\mathrm{~S}-2$ & S-3 & $\mathrm{S}-4$ & S-5 & $\mathrm{S}-1$ & $\mathrm{~S}-2$ & $S-3$ & $\mathrm{~S}-4$ & $\mathrm{~S}-5$ \\
\hline 1 & -107 & -98 & -99 & -102 & -94 & -99 & -95 & -91 & -101 & -94 & -92 & -103 & -88 & -91 & -81 \\
\hline 2 & -114 & -101 & -106 & $\mathrm{cc}^{*}$ & $\mathrm{cc}^{*}$ & -110 & -96 & -109 & -87 & $\mathrm{cc}^{*}$ & -113 & -103 & -112 & -99 & -94 \\
\hline ntv & -54 & -58 & -52 & -52 & -56 & -58 & -55 & -59 & -58 & -48 & -69 & -72 & -66 & -64 & -71 \\
\hline
\end{tabular}

$* \mathrm{cc}=$ Cannot be calculated, $\mathrm{ntv}=$ native, $\mathrm{S}=$ Series, Mol.1 $=\mathrm{CEG}-3, \mathrm{Mol} .2=\mathrm{HPG}-7$ 


\section{CONCLUSION}

Besides stichoposide, CEG-3 and HPG-7 have potential as an anticancer through protein of human kinesin-8. Both compounds provide a better grid score than stichoposide and native ligands.

\section{REFERENCES}

Cuong, N.X., L. Hoang, T.T.H. Hanh, N. Van Thanh and N.H. Nam et al., 2017. Cytotoxic triterpene diglycosides from the sea cucumber Stichopus horrens. Bioorg. Med. Chem. Lett., 27: 2939-2942.

Pangestuti, R. and Z. Arifin, 2018. Medicinal and health benefit effects of functional sea cucumbers. J. Traditional Complementary Med., 8: 341-351.
Park, E.S., S.H. Yun, S.W. Shin, J.Y. Kwak and J.I. Park, 2012. Induction of apoptosis and antitumor activity by stichoposide D through the generation of ceramide in human leukemia cells. J. Life Sci., 22: 760-771.

Purcell, S.W., A. Mercier, C. Conand, J.F. Hamel, M.V. Toral-Granda, A. Lovatelli and S. Uthicke, 2013. Sea cucumber fisheries: Global analysis of stocks, management measures and drivers of overfishing. Fish Fisheries, 14: 34-59.

Setyastuti, A. and P. Purwati, 2015. Species list of Indonesian trepang. SPC. Beche De Mer Inf. Bull., 35: 19-25.

Yun, S.H., E.S. Park, S.W. Shin, Y.W. Na and J.Y. Han et al., 2012. Stichoposide C induces apoptosis through the generation of ceramide in leukemia and colorectal cancer cells and shows in vivo antitumor activity. Clin. Cancer Res., 18: 5934-5948. 